\title{
Inotropic Support for Hemodynamic Decompensation During Acute Myocardial Transplant Rejection
}

\author{
G. Michael Deeb, MD, Steven F. Bolling, MD, Cynthia N. Steimle, MD, \\ Anne Lynn McKay, RN, and Ann Marie Richardson, RN
}

\begin{abstract}
LLOGENEIC orthotopic heart transplant $A$ rejection is common; however, associated acute hemodynamic decompensation at the time of rejection is rare. Improved immunosuppression and increased surveillance by serial endomyocardial biopsies are responsible for decreased mortality rates secondary to rejection. ${ }^{1,2}$ However, those patients who do develop hemodynamic instability with rejection require immediate support until reversal of rejection (ie, immunologic rescue) can occur. This report reviews the technique used at the University of Michigan for support of patients with acute hemodynamic decompensation following cardiac rejection.
\end{abstract}

\section{MATERIALS AND METHODS}

From January 1987 to December 1989, nine orthotopic heart transplant patients presented with the chief complaints of lethargy, weakness, and the feeling of not doing well. All patients had been previously well at home when the symptoms began. Each of the nine patients was anxious, cool to the touch, and had a grey, sallow appearance. All patients were admitted to the intensive care unit (ICU) and patients with a systemic systolic blood pressure (SBP) less than $90 \mathrm{~mm} \mathrm{Hg}$ were begun on intravenous (IV) catecholamine therapy. Pulmonary artery and radial arterial catheters were inserted and hemodynamic parameters, including systemic and pulmonary blood pressure (BP, PAP), central venous pressure (CVP), cardiac output and index $(\mathrm{CO}, \mathrm{Cl})$, and mixed venous oxygen saturation $\left(\mathrm{Sv}_{2}\right)$, were measured. A chest X-ray (CXR), electrocardiogram (ECG), arterial blood gas (ABG), and complete blood work, consisting of chemistries, hematologies, and cyclosporine levels, were obtained. Each patient was cultured for bacterial, fungal, viral, and other opportunistic organisms. Emergency endomyocardial biopsy was performed and graded according to the classification of Billingham. ${ }^{3}$ Grade 3 and 4

From the Section of Thoracic Surgery. University of Michigan Medical Center, Ann Arbor, MI.

Address reprint requests to G. Michael Deeb, MD, Director, Cardiac Transplants and Artificial Heart Program. The University of Michigan Medical Center, Section of Thoracic Surgery, 2124F Taubman Center, Box 0344, Ann Arbor, MI 48109.

(C) 1990 by W.B. Saunders Company. 0888-6296/90/0406-5004\$03.00/0 biopsy specimens were considered positive for acute myocardial transplant rejection, necessitating rescue immunologic therapy. Patients were volume loaded if necessary to a CVP greater than $10 \mathrm{~mm} \mathrm{Hg}$ and a pulmonary artery diastolic (PAD) pressure greater than $15 \mathrm{~mm} \mathrm{Hg}$. If the patient's systemic SBP was less than $90 \mathrm{~mm} \mathrm{Hg}$, IV catecholamines were administered. When the BP was greater than $90 \mathrm{~mm} \mathrm{Hg}$, PAD greater than $15 \mathrm{~mm} \mathrm{Hg}, \mathrm{CVP}$ greater than $10 \mathrm{~mm} \mathrm{Hg}$, and the SVR greater than 1,200 dyne $\cdot \mathrm{s} \cdot \mathrm{cm}^{-5}$ in association with a $\mathrm{Cl}$ less than $2 \mathrm{~L} / \mathrm{min} / \mathrm{m}^{2}$ and $\mathrm{SV}_{2}$ less than $50 \%$, amrinone was begun at a loading dose of $1.5 \mathrm{mg} / \mathrm{kg}$ followed by a continuous IV infusion of $10 \mu \mathrm{g} / \mathrm{kg} / \mathrm{min}$. The desired therapeutic effects of treatment were a CI greater than $2 \mathrm{~L} / \mathrm{min} / \mathrm{m}^{2}$ and a $\mathrm{S}_{\bar{O}} \mathrm{O}_{2}$ greater than $50 \%$. Once the diagnosis of acute myocardial transplant rejection was made, rescue therapy with IV bolus Solumedrol (Upjohn, Kalamazoo, MI) in association with either IV OKT3, murine monoclonal anti-CO3 antibody (orthoclone OKT3), or Minnesota antilymphocytic globulin (MALG) immunologic therapy was administered. When immunologic rescue therapy became effective, IV hemodynamic drug support was weaned and discontinued.

\section{RESULTS}

Eighty-nine adult heart transplant patients underwent 371 endomyocardial biopsies over 36 months. One hundred twelve $(30 \%)$ of the 371 biopsy specimens showed acute myocardial transplant rejection. Only nine of the $112(8 \%)$ with rejection had acute hemodynamic decompensation. Seven of the nine patients $(78 \%)$ required immediate IV catecholamine therapy for BP less than $90 \mathrm{~mm} \mathrm{Hg}$, and two of seven (29\%) responded to a combination of dobutamine and dopamine at $10 \mu \mathrm{g} / \mathrm{kg} / \mathrm{min}$ each with a resulting CI greater than $2 \mathrm{~L} / \mathrm{min} / \mathrm{m}^{2}$ and $\mathrm{S}_{\overline{\mathrm{V}}} \mathrm{O}_{2}$ greater than $50 \%$. However, five of these seven patients (71\%) required additional therapy with IV amrinone to reach the desired therapeutic effect. The remaining two patients presented with a BP greater than $90 \mathrm{~mm} \mathrm{Hg}$ and did not require immediate catecholamine therapy; however, their $\mathrm{CI}$ and $\mathrm{SviO}_{2}$ were less than the desired levels, and in addition their SVR was greater than 1,200 dyne $\cdot \mathrm{s} \cdot \mathrm{cm}^{-5}$ so that they were treated with and responded to amrinone therapy alone. Therefore, seven of nine $(78 \%)$ patients required amrinone therapy for successful treatment of acute myo- 


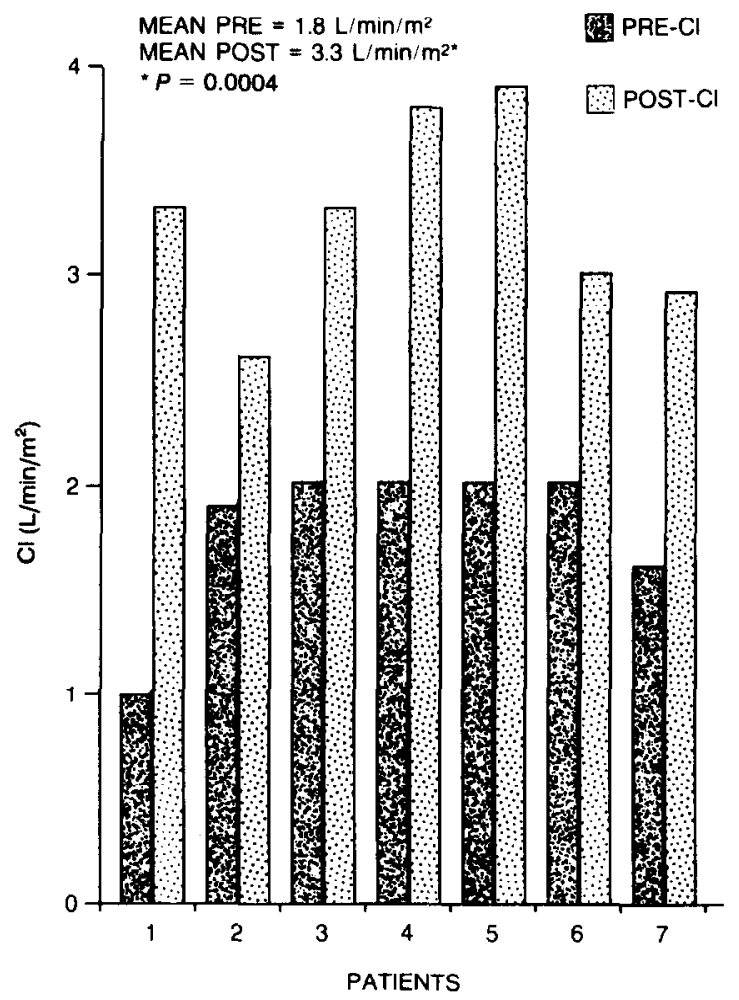

Fig 1. The $\mathrm{Cl}$ for the seven patients treated with amrinone. The dark bars represent values prior to amrinone therapy: the light bars represent values after amrinone therapy. The numbers in the top left-hand comer represent the mean value for all seven patients. There is a significant difference between the postamrinone value and the preamrinone value at $P<0.05$ level.

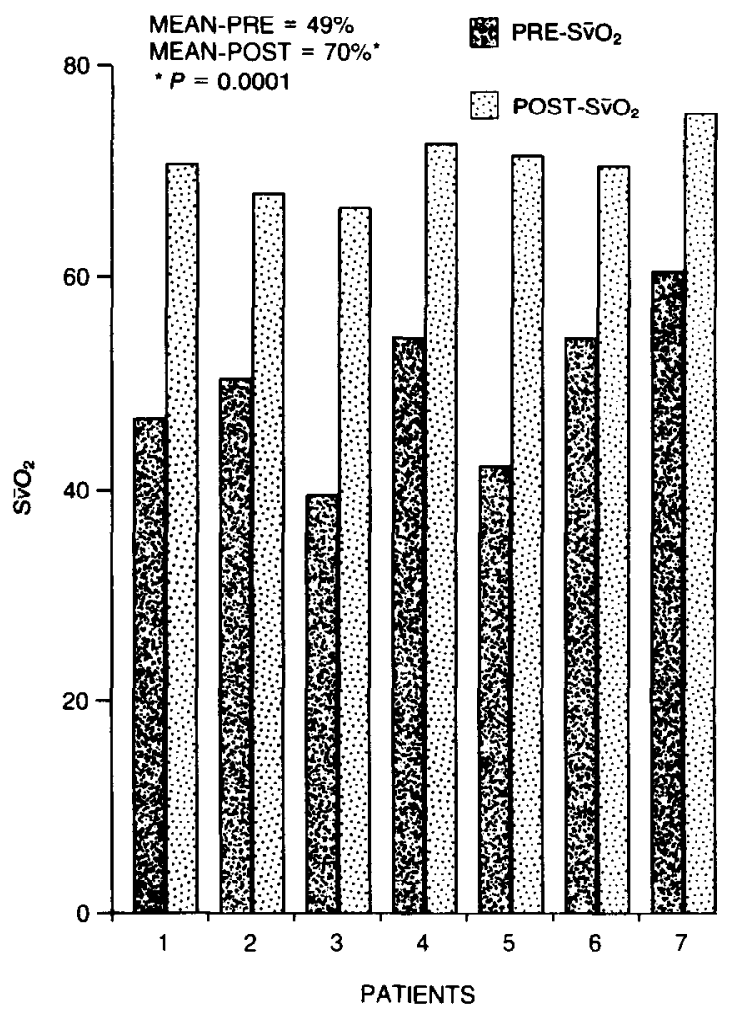

Fig 2. The $\mathrm{Sv}_{2} \mathrm{O}_{2}$ saturation for the seven patients treated with amrinone. The dark bars represent values prior to amrinone therapy: the light bars represent values after amrinone therapy. The numbers in the top left-hand corner represent the mean value for all seven patients. There is a significant difference between the postamrinone value and the preamrinone value at $P<0.05$ level.

Table 1. Hemodynamic Parameters Before and After Amrinone Therapy

\begin{tabular}{|c|c|c|c|c|}
\hline Parameter & No. of Patients & Preamrinone & $P$ Value & Postamrinone \\
\hline Temperature $\left({ }^{\circ} \mathrm{C}\right)$ & 7 & $36.6 \pm 0.3$ & 0.26 & $36.4 \pm 0.4$ \\
\hline Respiratory rate (breaths/min) & 7 & $22.0 \pm 1.0$ & 0.46 & $21.0 \pm 1.0$ \\
\hline Heart rate (beats/min) & 7 & $109 \pm 8.0$ & 0.31 & $103 \pm 5.0$ \\
\hline SAS (mm Hg) & 7 & $120 \pm 7.0$ & 0.77 & $118 \pm 5.0$ \\
\hline $\mathrm{SAD}(\mathrm{mm} \mathrm{Hg})$ & 7 & $82.0 \pm 6.0$ & 0.40 & $77.0 \pm 4.0$ \\
\hline SAM $(\mathrm{mm} \mathrm{Hg})$ & 7 & $94.0 \pm 7.0$ & 0.56 & $91.0 \pm 4.0$ \\
\hline PAS (mm Hg) & 7 & $41.0 \pm 2.0$ & $0.0028^{*}$ & $35.0 \pm 3.0$ \\
\hline $\mathrm{PAD}(\mathrm{mm} \mathrm{Hg})$ & 7 & $23.0 \pm 2.0$ & 0.06 & $17.0 \pm 2.0$ \\
\hline PAM (mm Hg) & 7 & $29.0 \pm 1.0$ & $0.01^{*}$ & $22.0 \pm 2.0$ \\
\hline $\mathrm{CVP}(\mathrm{mm} \mathrm{Hg})$ & 7 & $15.0 \pm 2.0$ & $0.03^{\circ}$ & $11.0 \pm 2.0$ \\
\hline $\mathrm{CO}(\mathrm{L} / \mathrm{min})$ & 7 & $3.30 \pm 0.3$ & $0.0005^{*}$ & $6.0 \pm 0.3$ \\
\hline $\mathrm{Cl}\left(\mathrm{L} / \mathrm{min} / \mathrm{m}^{2}\right)$ & 7 & $1.80 \pm 0.1$ & $0.0004^{*}$ & $3.3 \pm 0.2$ \\
\hline SVR (dyne $\cdot \mathrm{s} \cdot \mathrm{cm}^{-5}$ ) & 7 & $2,008 \pm 233$ & $0.002^{*}$ & $1,009 \pm 80$ \\
\hline $\mathrm{SvO}_{2}(\%)$ & 7 & $49.0 \pm 3.0$ & $0.0001^{*}$ & $70.0 \pm 1.0$ \\
\hline
\end{tabular}

Abbreviations: SAS, systemic arterial systolic pressure; SAD, systemic arterial diastolic pressure; SAM, mean systemic arterial pressure; PAS, pulmonary arterial systolic pressure; PAD, pulmonary arterial diastolic pressure; PAM, mean pulmonary arterial pressure; CVP, central venous pressure; $\mathrm{CO}$, cardiac output; $\mathrm{Cl}$, cardiac index; $\mathrm{SVR}$, systemic vascular resistance; $\mathrm{SṽO}_{2}$, systemic venous oxygenation.

* Significant at the $P<0.05$ level. 


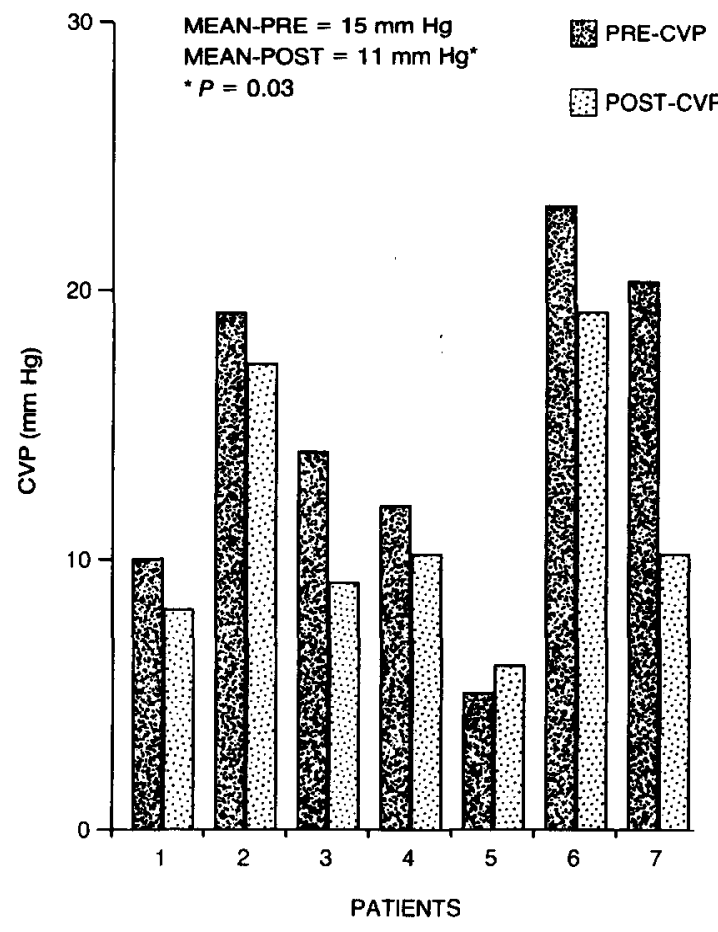

Fig 3. The CVP for the seven patients treated with amrinone. The dark bars represent values prior to amrinone therapy: the light bars represent values after amrinone therapy. The numbers in the top left-hand corner represent the mean value for all seven patients. There is a significant difference between the postamrinone value and the preamrinone value at $P<0.05$ level.

cardial transplant rejection with hemodynamic decompensation (Figs 1 and 2). In addition, the mean CVP, mean PAP (or PAM), and SVR of the patients treated with amrinone were significantly lowered (Table 1) (Figs 3, 4, and 5). All nine patients were successfully immunologically rescued with antirejection therapy and weaned from inotropic drug support. No patients required mechanical hemodynamic support.

\section{DISCUSSION}

Improvements in immunosuppression therapy, including induction using monoclonal or polyclonal antibodies, as well as chronic triple drug therapy consisting of cyclosporine, azathioprine, and prednisone, have markedly decreascd the incidence of mortality due to rejection. ${ }^{4-6}$ As demonstrated in the present series, acute myocardial transplant rejection associated with acute hemodynamic decompensation is rare $(9 / 112$, $8 \%$ ). However, when this diagnosis is entertained immediate hemodynamic support is necessary while prompt diagnosis is established and rescue immunologic therapy can be instituted.

The histological findings of grade 3 and 4 acute myocardial transplant rejection include lymphocytic infiltrates with marked myocardial edema and associated myocellular necrosis. In addition, grade 4 demonstrates interstitial hemorrhage and polymorphonuclear cell invasion. Unfortunately, there is no direct correlation between the level of rejection and the likelihood and severity of hemodynamic decompensation with acute myocardial transplant rejection, because five of nine $(55 \%)$ of these patients had grade 3 rejection. Furthermore, there is no way to predict from the histological findings on endomyocardial biopsy whether a patient will have acute hemodynamic decompensation or not (ie,

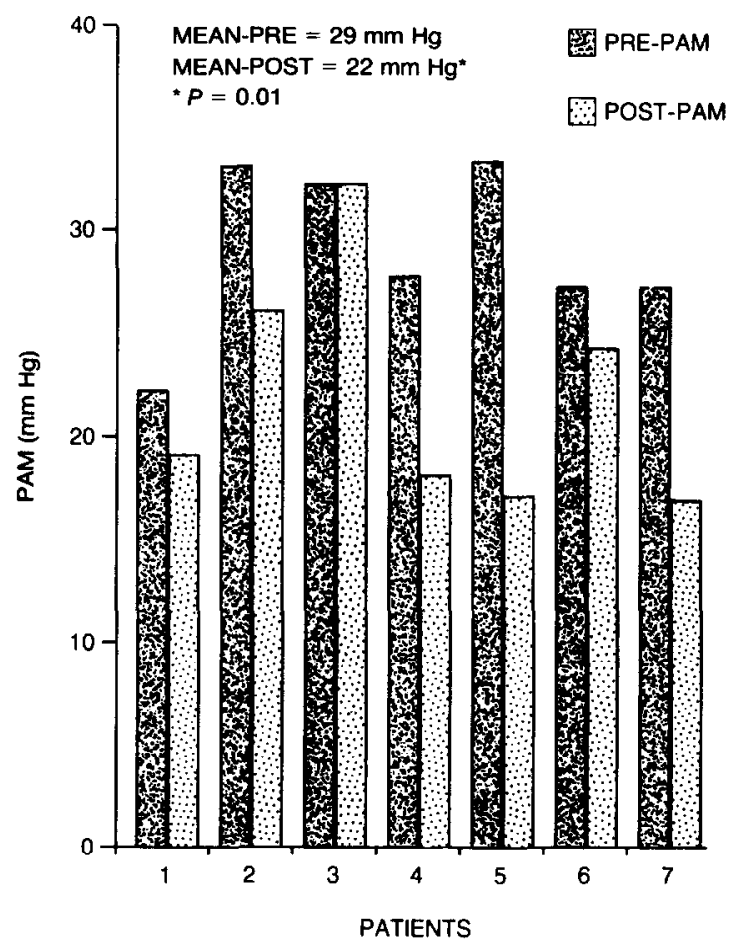

Fig 4. The PAM for the seven patients treated with amrinone. The dark bars represent values prior to amrinone therapy; the light bars represent values after amrinone therapy. The numbers in the top left-hand corner represent the mean value for all seven patients. There is a significant difference between the postamrinone value and the preamrinone value at $P<0.05$ level. 


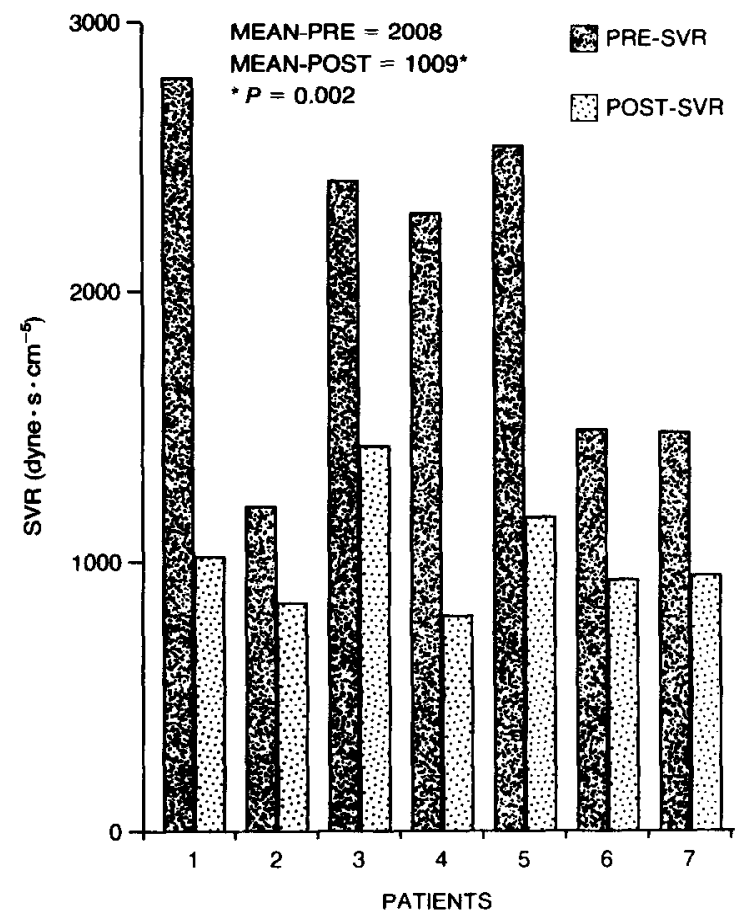

Fig 5. The SVR for the seven patients treated with amrinone. The dark bars represent values prior to amrinone therapy; the light bars represent values after amrinone therapy. The numbers in the top left-hand corner represent the mean value for all seven patients. There is a significant difference between the postamrinone value and the preamrinone value at $P<0.05$ level.

two patients may have identical histological findings on biopsy with markedly different hemodynamics).

Myocellular swelling and necrosis decrease not only the number of functioning myocytes but also the effectiveness of the remaining cells. Cyclic changes in cytosolic calcium concentrations are altered in rejection due to cellular swelling. This causes alterations in function of the voltage-dependent gated slow channels and the nongated ionic channels for sodium-calcium exchange as well as release and reuptake by the sarcoplasmic reticulum calcium pump. This inhibition of free calcium flux affects actin and myosin cross- bridging through the troponin complex and, therefore, decreases the force of contraction during systole and the ability of the ventricle to relax during diastole. . $^{70}$

Cyclical variations in intracellular free calcium are governed by cyclic adenosine monophosphate (CAMP), which regulates the activity of intracellular calcium channels and pumps. ${ }^{11-13}$ Optimizing the levels of intracellular cAMP would maximize calcium flux and subsequent ventricular function. Catecholamines stimulate $\beta$-receptors on the cell membrane to produce adenylate cyclase, which promotes the production of cAMP. Phosphodiesterase (PDE) inhibitors also increase the levels of cAMP by blocking its breakdown. ${ }^{14,15}$

Combination therapy appears to have the most beneficial effect on hemodynamics during rejection, possibly due to a synergistic action on cAMP. PDE inhibition therapy may also be helpful in the treatment of unstable hemodynamics during rejection secondary to its peripheral vasodilatory qualities, with subsequent unloading of the ventricles with a resultant decrease in the force necessary for contraction.

Certainly in this patient population, amrinone was necessary in the majority of patients (78\%) to attain adequate $\mathrm{CI}\left(>2 \mathrm{~L} / \mathrm{min} / \mathrm{m}^{2}\right)$ and tissue perfusion $\left(\mathrm{S}_{\bar{v}} \mathrm{O}_{2}>50 \%\right)$. The improvement in myocardial performance was secondary to the peripheral vasodilatory effect of amrinone as noted by the significant decrease in the SVR as well as an increase in contractility shown by the significant increase in CI without a change in heart rate.

Therefore, it is concluded that acute myocardial transplant rejection with acute hemodynamic decompensation must be treated aggressively with rapid diagnosis, effective rescue immunosuppressive therapy, and hemodynamic support until resolution of the rejection. Combination $\beta$-adrenergic stimulation and PDE therapy may be the most effective treatment, due to synergism of action.

\section{REFERENCES}

1. Oyer PE, Stinson EB, Jamieson SWS, et al: Cyclosporin in cardiac transplantation: A $2 \frac{1 / 2}{2}$ year follow-up. Transplant Proc 15:2546-2552, 1983

2. Caves DK, Stinson EB, Billingham ME, et al: Di- agnosis of human cardiac allograft rejection by serial cardiac biopsy. J Thorac Cardiovasc Surg 66:461-466, 1973

3. Billingham ME: Diagnosis of cardiac rejection by endomyocardial biopsy. J Heart Transplant 1:25-30, 1982 
4. Renlund DG, O'Connell JB, Gilbert EM, et al: Feasibility of discontinuation of corticosteroid maintenance therapy in heart transplantation. J Heart Transplant 6:71-78, 1987

5. Oyer PE: Triple drug immunosuppressive therapy in cardiac transplantation. Transplant Immunol Lett 3:3, 1986

6. Bolman RM, Elick B, Olivari MT, et al: Improved immunosuppression for heart transplantation. J Heart Transplant 4:315-318, 1985

7. Fabiato A, Fabiato F: Calcium and cardiac excitation-contraction coupling. Annu Rev Physiol 41:473-484, 1979

8. Wohlfart B, Nobel MIM: The cardiac excitationcontraction cycle. Pharmacol Ther 16:1-43, 1982

9. Colucci WS, Wright RF, Braunwald E: New positive inotropic agents in the treatment of congestive heart failure. N Engl J Med 314:290-297, 1986
10. Chidsey CA, Braunwald E: Sympathetic activity and neurotransmitter depletion in congestive heart failure. Pharmacol Rev 18:685-700, 1966

11. Chapman RA: Control of cardiac contractility at the cellular level. Am J Physiol 245:H535-H552, 1983

12. Braunwald E, Sonnenblick EH, Ross J Jr: Contraction of the normal heart, in Braunwald E (ed): Heart Disease: A Textbook of Cardiovascular Medicine (ed 2). Philadelphia, PA, Saunders, 1984, pp 409-446

13. Winegrad S: Calcium release from cardiac sarcoplasmic reticulum. Annu Rev Physiol 44:45I-462, 1982

14. Benotti JR, Grossman W, Braunwald E, et al: Hemodynamic assessment of amrinone. N Engl J Med 299:13731377,1987

15. Mancini D, LeJemtel TH, Sonnenblick EH: Intravenous use of amrinone for the treatment of the failing heart. Am J Cardiol 56:8B-15B, 1985 